\title{
Shared action: An existential phenomenological account
}

\author{
Nicolai Knudsen ${ }^{1}$
}

Accepted: 6 October 2021

(c) The Author(s) 2021

\begin{abstract}
Drawing on recent phenomenological discussions of collective intentionality and existential phenomenological accounts of agency, this article proposes a novel interpretation of shared action. First, I argue that we should understand action on the basis of how an environment pre-reflectively solicits agents to behave based on (a) the affordances or goals inflected by their abilities and dispositions and (b) their selfreferential commitment to a project that is furthered by these affordances. Second, I show that this definition of action is sufficiently flexible to account for not only individual action (in which both (a) and (b) refer only to an individual) but also several distinct subtypes of shared action. My thesis is that behaviour counts as shared action if and only if it is caused by a solicitation in which either (a) the goals, or (b) the commitments, or both (a) goals and (b) commitments are joint, i.e., depend on several individuals. We thereby get three distinct subtypes of shared actions: (i) jointly coordinated individually committed action, (ii) individually coordinated jointly committed action, and (iii) jointly coordinated jointly committed action.
\end{abstract}

Keywords Collective intentionality $\cdot$ Shared action $\cdot$ Plural self-awareness $\cdot$ Joint commitments $\cdot$ Joint goals

Human beings often act together. They dance, paint houses, and go for walks with each other. It is widely recognised that shared actions such as these are not simply aggregates of individual actions. ${ }^{1}$ Rather, if two or more people are to act together, their actions and intentions must interrelate, so that each person's actions constitutively depend on the other people's actions. This interdependence must be

\footnotetext{
1 As I use the term, "shared action" refers to any intentional activity in which we are immediately aware that it constitutively depends on other people. Construed this way, "shared action" is an umbrella term that covers several distinct forms of action with different degrees and types of intersubjective cooperation. "Joint action" is the subtype of shared action with the highest degree of cooperation, namely, jointly coordinated and jointly committed action (cf. Section 5).
}

Nicolai Knudsen

nicolai.knudsen@philosophy.ox.ac.uk

1 Linacre College, University of Oxford, Oxford, United Kingdom 
immediately obvious to the co-agents so that they are aware that they act together rather than individually. It is widely acknowledged that our capacity for shared action is a central condition of possibility of human civilisation at large (e.g. Searle, 1995, 2010; Tomasello, 2014; Tomasello \& Carpenter, 2007), yet it is conceptually unclear what exactly shared action is and how it differs from individual action.

One of the reasons for this incertitude is, or so I shall argue, that the dominant approaches to shared action and intentions (Bratman, 1999, 2013; Gilbert, 1990, 2013; Searle, 1990, 2010) presuppose an overly intellectualist model of action that is largely at odds with the phenomenology of action, i.e., with how minded agents typically understand themselves and what they do in everyday activities. Given that shared action requires that we are aware that we act together, we must get the phenomenology right. Recently, some work has been put forth that aims to correct the intellectualism of the dominant approaches (e.g. Schmid, 2014a, b, 2018; Zahavi, 2015a, b, 2018, 2019), but I will argue that these approaches do not go far enough in their phenomenological reinterpretations of shared agency. Instead, I will draw upon the model of agency advanced by existential phenomenologists like Heidegger (1962), Merleau-Ponty (2012), and Dreyfus (2014) to spell out the phenomenological structure of shared action. I argue that a specific form of agency-what I call pre-reflective agency-is best explained as the way in which an environment solicits us to act. As I use the terms, solicitations differ from affordances insofar as affordances can be inert. Solicitations, in contrast, are affordances that prompt actions because the relevant agent is committed to some underlying project that is furthered through these affordances. Extending this line of thought, I will argue that some solicitations prompt shared action. They do so either because they solicit several agents to cooperate (that is, to act on shared affordances) or because they solicit an agent or several agents to act to further a (joint) project (that is, to act due to a (joint) commitment).

I first outline some of the problems characteristic of contemporary approaches to shared action (Section 1), and then I suggest that these problems can be avoided if we construct our model of shared action on the account of pre-reflective action found in existential phenomenology rather than the standard account of reflective action (Section 2). Since, however, the phenomenology of action is typically formulated in individualistic terms, I combine it with the idea of plural pre-reflective selfawareness to show how solicitations can be given to a group rather than an individual (Section 3). I then analyse solicitations in terms of (a) affordances inflected by someone's abilities and dispositions and (b) someone's self-referential commitment to a project furthered by these affordances (or, in short, in terms of (a) goals and (b) commitments) (Section 4). Drawing on this analysis, I construct a phenomenologically plausible taxonomy of individual and shared actions that incorporate both teleological and normative elements of pre-reflective shared actions (Section 5). 


\section{What is shared action? Some preliminaries}

I take it that a successful account of shared action must satisfy the following three conditions $^{2}$ :

(1) The plurality condition: Shared action requires multiple ontologically similar agents.

(2) The coalescence condition: Shared action requires that the plurality of agents form a collective.

(3) The awareness condition: Shared action requires that the involved agents are aware of what they are doing.

These conditions provide a good starting point because if we leave out one of the conditions, we contradict our basic intuition of what shared action is. The combination of plurality and awareness without coalescence wrongfully takes aggregated individual intentions, e.g. a group of people sitting on the bus minding their own business, to be a form of shared action. If we combine plurality and coalescence without the awareness condition, we wrongfully come to include many other activities than just actions. For instance, we might have a plurality of agents who have formed a collective (say, a book club), yet only some of their activity will count as shared action. It might be true for all members of the book club that they inadvertently shake their legs under the table, but this activity does not count as a shared action since the agent or agents must be aware of what they are doing in a specific way in order for it to count as an action. Lastly, the coalescence condition and the awareness condition without the plurality condition lead to something like a hive mind, i.e., several discrete bodies linked together in a single consciousness.

Since aggregated individual intentions fail to fulfil the coalescence condition, and since the awareness condition requires that we locate whatever glue makes our individual actions coalesce into a single shared action immanently in the minds of the co-agents, it seems that any account of shared action must show that the intentions of the co-agents are somehow interdependent. What constitutes this interdependence?

Let us take a closer look at two of the most influential accounts, Michael Bratman's and Margaret Gilbert's. Bratman proposes that this interdependence requires you and me to intend that we $J$ together and that we are mutually responsive to each

\footnotetext{
2 A similar idea can be found in Searle (1990, p. 414) and is formulated as a list of desiderata in Mathieson (2005) and Walsh (2019). Some scholars assume that the coalescence condition and the awareness condition only obtain when there is common knowledge (or mutual belief) between the agents, but as Kirk Ludwig has argued this is too demanding since one can arguably engage in shared action with others even if one does not know or believe that others will do their part but for instance simply hopes that they will (Ludwig, 2016, pp. 219-221). I do not think that we can do away with these conditions, but I agree that the approaches criticised by Ludwig are too demanding. In the following, I will argue in favor of a non-intellectual way of reconciling the coalescence condition and the awareness condition by appealing to the way in which some forms of pre-reflective action tacitly assumes that others will do their part.
} 
other by tracking each other's intentions and actions (cf. Bratman, 2013, pp. 78-84). More specifically, Bratman argues that we intend $J$ if and only if

(1) (a) I intend that we $J$ and (b) you intend that we $J$,

(2) I intend that we $J$ in accordance with and because of (1)(a), (1)(b), and meshing subplans of (1)(a) and (1)(b); you intend that we $J$ in accordance with and because of (1)(a), (1)(b) and meshing subplans of (1)(a) and (1)(b),

(3) (1) and (2) are common knowledge between us. (Bratman, 1999, p. 131)

This account is "reductive in spirit" (Bratman, 1999, p. 108) because it reduces shared actions and intentions to interdependent individual actions and intentions. These are interdependent because each agent has the collective intention as its object while being responsive to the other agent and while operating under conditions of common knowledge.

Margaret Gilbert argues against this reductionism that the coalescence condition can only be satisfied by a plural subject. A plural subject comes about when two or more people express their readiness to undertake a joint commitment, e.g. go for a walk (Gilbert, 1990). This commits the individuals "to emulate as best they can a single body" espousing a goal (Gilbert, 2013, p. 33). The gist of Gilbert's argument is that once the relevant individuals express their readiness to form a plural subject and this is common knowledge between them, they each have a reason to behave in a specific way. Whereas Bratman takes a joint goal to suffice, Gilbert stresses that individuals only coalesce when they are tied together normatively. Recalling that they expressed their readiness to undertake the joint commitment (through, for instance, an explicit agreement), each member of the plural subject is entitled to rebuke others if they violate the joint commitment, and, in contrast, to personal commitments, these commitments cannot be rescinded unilaterally. For instance, in walking together, each participant can blame the other for walking too fast, for not showing up on time, and so on.

At the face of it, these accounts are quite different as they locate the coalescence in different elements of the intention. Bratman focuses mainly on the intentional object while Gilbert focuses on the intentional subject. In addition, they disagree on whether shared action is teleological (Bratman) or essentially normative (Gilbert). However, their accounts also have certain similarities by virtue of which, I contend, they both face three similar problems.

The first problem, which I'll call the genetic problem, concerns the transition from individual intentions to collective intentions. In Bratman's case, the individual intentions of (1)(a) and (1)(b) have we $J$ as their intentional object but this means that the individuals already possess an understanding of what they can do collectively prior to establishing the interdependence ((1)-(3)) that supposedly makes shared intentions possible (cf. Petersson, 2007). ${ }^{3}$ Gilbert, on her part, grounds

\footnotetext{
3 In a reply to Petersson, Bratman argues that his account avoids the threat of circularity since (1), which is supposed to explain what shared intentionality is, does not have an instance of shared intentionality as its object. Instead, Bratman argues that "we $J$ " in (1) refers to a joint activity that is "neutral with respect to shared intentionality" (Bratman, 2013, p. 46). If I understand it correctly, the suggestion is that condition (1)-(3) explains what it is for us to reflectively endorse and undertake some joint activity. For
} 
collective intentionality in joint commitments and argues that joint commitments are generated when individuals communicate their readiness to undertake such a commitment. Some argue that communication is itself an instance of collective intentionality, and if this is the case, Gilbert's account leads to an infinite regress, where a joint commitment presupposes communication, which, in turn, presupposes a joint commitment and so forth (cf. Schmid, 2009; Schweikard \& Schmid, 2013). Thus, the transition from individual intentions to collective intentions constitutes a problem for both Bratman and Gilbert.

The second problem, which I call the taxonomy problem, concerns the question whether Bratman and Gilbert target the same phenomena. The disagreement is often described as a contradiction between theoretically incompatible positions, but perhaps Gilbert and Bratman simply describe different phenomena-e.g. normative vs. teleological types of interaction. If this is the case, the problem is no longer to provide one simple formula for all types of shared actions and intentions but rather to come up with a suitably nuanced taxonomy capable of integrating their respective target phenomena.

The third problem - the intellectualist problem - concerns how Bratman and Gilbert accounts for the awareness condition. They disagree on whether shared action requires that we normatively rely on or non-normatively predict the behaviour of others but both argue that the awareness condition only obtains under conditions of common knowledge (e.g. Bratman, 2013, pp. 57-59; Gilbert, 1992, pp. 189-191, 2013 , p. 43). In addition, they both subscribe to a fairly standard model of agency according to which a piece of behaviour counts as action only if it is guided by certain occurrent mental states. For Gilbert, for instance, when joint commitments come into conflict with other desires on our part, we must actively remind ourselves of our obligation(s) to the other members of the plural subject. Some have questioned the adequacy of this model by distinguishing different kinds of self- and other-awareness. Phenomenologists in particular argue that an adequate understanding of shared actions and we-experiences in general require that we cash out the awareness condition in pre-reflective terms (e.g. Schmid, 2014a, 2018; Walsh, 2019; Zahavi, 2015a, 2019). Similarly, it can be argued from an action-theoretic point of view that the relation between actions and mental states such as intentions, beliefs, and desires are far more elusive than Gilbert and Bratman assume. In this vein, existential phenomenologists like Heidegger (1962), Merleau-Ponty (2012), and Dreyfus (2014) claim that actions do not involve an awareness of certain mental states

\footnotetext{
Footnote 3 (continued)

Bratman, to have an intention to do something is to plan to do it in the sense of settling on a goal and deliberating on the means to achieve it (Bratman, 2013, p. 15). In other words, there is no circularity in saying that we intend $J$ only if you and I each intend that we $J$, since the instance of "we intend $J$ " that appears in the analysandum refers to us having reflectively endorsed and undertaken (that is, us having planned to) $J$, while the "we $J$ " that appears in the analysans refers to a joint activity without this reflective endorsement. Formulated in this way, Bratman clearly presupposes that we are already aware of possible joint activities prior to forming a full-blown shared plan. In emphasizing pre-reflective rather than reflective action (see next section), I want to pose the question: How are we aware of what we can do prior to our reflection or deliberation?
} 
and that the dominant approaches to the philosophy of action commit an intellectualist error that flies in the face of everyday experiences.

\section{Pre-reflective and reflective action}

In the philosophy of action, a form of intellectualism is often introduced by the need to distinguish mere bodily happenings from actions. It counts as an action if I raise my arm when dancing in a nightclub, but not when my arm is raised because someone else controls it through an implanted microchip. When discussing individual action, it is typically argued that bodily movement counts as action only if the movement is justified or caused by a reason, i.e., if it stands in a particular relation to certain mental states such as desires and beliefs. If we try to expand this conception of individual agency to also cover cases of shared agency, the number of mental states that must be entertained by the co-agents multiplies. For Bratman, for instance, the shared intention that we $J$ involves not only that I desire that I do my part of $J$ and that I believe that I can do so by undertaking certain subplans, but that I also intend that you do your part of $J$ (e.g., that you have the appropriate desires and beliefs), and that this is common knowledge between us. Gilbert argues that it must be common knowledge between the participants in the plural subject that they are all similarly committed to espousing a goal and that they are all are committed to taking the individual steps necessary to reach this goal. In order to be plurally committed, I must presumably know what the goal is, believe that certain steps will help us obtain that goal, be aware that I have an obligation to help achieve this goal, and I must know that my co-agents also have the relevant knowledge, beliefs, and awareness of their obligations, including knowledge about my knowledge, beliefs, and so on.

In short, things quickly get extremely complicated, and there are reasons to question whether this model of agency provides a plausible explanation of all actions. First, the resulting account of shared action, with its proliferation of mental states, seems to be overly demanding since even young children are capable of engaging in shared action. Second, and even more fundamentally, it is questionable that we are consciously aware of the mental states that presumably guide our actions in the way that standard philosophy of action suggests. In this vein, phenomenologists have argued that we often engage in intentional activity without being aware of the desires and beliefs that supposedly distinguish our actions from mere bodily movements. As Heidegger notes, we often open doors without ever thinking about their handles (Heidegger, 1962, p. 96). Similarly, to take an example from Dreyfus (2014, p. 84), Larry Bird reports that he would often pass the basketball to his team mates and only realise that he had passed it a moment later. In both cases, the agents have no conscious representation of the reasons that cause or justify their actions, yet it seems highly implausible to equate their activity with mere bodily movement of the kind that could have been induced by an implanted microchip.

This suggests that there is an intermediary level between bodily happenings and the type of actions described in standard philosophy of action. Let us call this intermediary kind of activity for pre-reflective action. To get a first approximation of what pre-reflective action is, we can contrast it with bodily happenings, 
on the one hand, and reflective actions, on the other hand. Pre-reflective action is distinct from bodily happenings since it requires that we are aware of ourselves as the ones performing the action in question. Yet, in contrast to reflective action, pre-reflective action does not require that we consciously represent our desired goals, our beliefs about how to achieve them, and, in cases of shared action, our knowledge about our co-agents. In reflective actions, we are hence aware that our actions are guided by certain identifiable mental states. In contrast, pre-reflective (or "fluid") actions are, to borrow a formulation from Mark Wrathall, "experienced, not as the deliberative outcome of my aims and desires and beliefs, but as being drawn out of me directly and spontaneously by the particular features of the situation, without the mediation of occurrent mental or psychological states or acts" (Wrathall, 2014, p. 195). In pre-reflective action, I respond to the solicitations of my environment without reflecting on what I do. Rather than feeling that our mental states exercise control over our bodily movements, "we experience the situation as drawing the action out of us" (Dreyfus, 2014, p. 82).

As an intermediary activity, the concept of pre-reflective action might seem rather unstable. Coming from the direction of reflective action, we might ask what it is to "consciously represent" certain mental states? John Searle has, for instance, argued that an agent might have a representational attitude (that is, an attitude with identifiable conditions of satisfaction that can be stated propositionally) without, however, consciously thinking a linguistic propositional thought (Searle, 2001, p. 277f). On a more relaxed reading, one might thus argue that all it takes for behaviour to count as action is that the agent is able to declare what she is doing as well as the means necessary to do it. However, there is evidence that even this relaxed reading of reflective action does not do justice to many everyday activities. It is often reported by, for instance, expert athletes and musicians that they 'go into flow' in such a way that they cannot explicitly state the steps they undertake or the conditions of satisfactions that makes them succeed (for discussions, see Dreyfus \& Dreyfus, 1988; Høffding, 2019). As Dreyfus once put it, in pre-reflective action "my absorbed response must lower a tension without my knowing in advance how to reach equilibrium or what it would feel like to be there" (Dreyfus, 2014, p. 150). This suggests that some forms of actions cannot be represented or subjected to reflection, while we are performing them. But this opposition between action and representation is not only characteristic in the very moment of action. Some forms of intentional activity seem to resist explication all together. As a case in point, consider the phenomenon known as "the twisties" in which a gymnast suddenly forgets how to do a twist. This happened to the US gymnast Simone Biles during the 2020 Olympics in Tokyo. Presumably, the cause of the twisties is that the gymnast, perhaps due to the pressure of a big competition, comes to reflect on what is normally done pre-reflectively. As Biles later reported on social media, her mind and body were somehow out of sync, and from the reflective stance brought about by her sudden lack of confidence in her usual bodily and pre-reflective action, she could no longer "fathom" or "comprehend" what it was to do a twist. If this is correct, we would be hard-pressed to say that an expert performer like Biles would have "beliefs" about what it is to do a twist in anything but a metaphorical sense. For her, the intentional activity 
of doing a twist is disturbed by reflection, and even afterwards, when reflecting on what went wrong and how she usually does a twist, her pre-reflective action seems to resist reflection and explication altogether.

Similarly, it is quite plausible that many shared actions can only take place if they are not disturbed by conscious deliberation and reflection. Consider, for instance, two people dancing "freestyle" in a nightclub. Some of their movements are likely to be consciously represented as when one dancer thinks to himself that in four beats, he will do a spin. Yet, most of their movements will be spontaneous and intuitive. When the dancers are "in the zone," they do not know how they place their limbs; they simply respond to the music and to each other fluidly and without thinking. Were one of them to reflect on their own movements or the movement of the other dancer, he would presumably feel out of sync not only with his own body but also with the other dancer and with the music. This constitutes an intersubjective version of the twisties.

Coming from the other direction, one might want to press the distinction between pre-reflective actions and bodily happenings. If, as we saw Wrathall claim above, pre-reflective action is "drawn out of me directly and spontaneously by the particular features of the situation," how is that any different from a mere reflex, e.g., when my lower leg kicks in response to the doctor taping my patellar tendon? Dreyfus occasionally defends the extreme view that pre-reflective action lacks all self-awareness (1991, p. 67), but this, I believe, erases the distinction between bodily happenings and pre-reflective actions by making pre-reflective agents out to be a form of well-functioning zombies. In contrast, I will argue that the key to this question is that in pre-reflective action we have a special kind of awareness of ourselves as the ones performing the pre-reflective action, although we must be careful not to assume that this self-awareness must be explained in intellectually demanding terms such as those of desire, belief, and knowledge. In other words, if pre-reflective agents are not simple zombies, there must be some measure of success that is immanent to pre-reflective actions. The pre-reflective agent must be aware of him- or herself as successfully performing the relevant action. In the paradigm case, we must be aware not just that a bodily movement is caused by certain environmental features; instead, we must be aware of ourselves as those responding to a given solicitation. To get a clearer view of this immanent measure of success and, especially, how it relates to shared and not just individual action, we must discuss the nature of pre-reflective self-awareness in more detail.

\section{Self-awareness in action}

Phenomenological theories of action tend to focus on individual pre-reflective action, so we need to show that pre-reflective attitudes can refer to groups and, thus, help us explain the phenomenon of shared action. In this regard, Hans Bernhard Schmid's account of plural self-awareness looks particularly promising. His view is, roughly, that an attitude is collective iff we are plurally self-aware of it as ours. The plural self-awareness thesis inscribes our coalescence into the very fabric of intentionality in a way that does not rely on us being thematically oriented towards 
each other or on us holding each other responsible in light of communicatively instituted commitments. In line with the phenomenological tradition, Schmid argues that self-awareness does not arise after a subject has reflected on itself, but is rather an immanent feature of an intentional act so that whenever the subject directs itself towards some object in the world it has an implicit awareness of itself as having that experience and being thus directed. In the case of plural self-awareness, we have a pre-reflective and non-thematic awareness that certain attitudes (e.g. perceptions) are ours, collectively (rather than mine, individually, or yours and mine, distributively) (Schmid, 2014a, p. 18). Consider, for instance, the difference between me watching a beautiful sunset while walking alone and us watching a beautiful sunset while walking together. Schmid's claim is that in the latter case we are plurally selfaware of watching the sunset together in a way that is phenomenally obvious to us and does not require that we reflect on each other's presence.

More specifically, Schmid argues that three features of our pre-reflective singular self-awareness can be translated into the plural: (i) In terms of ownership, plural self-awareness is "the basic way in which (...) collective intentions or beliefs are transparent to ourselves as ours." It is what "formally unifies our social mind" (Schmid, 2014a, p. 17). (ii) In terms of perspective, "[singular] [s]elf-awareness draws a distinction between the mind, as a formally unified whole, from the world" (Schmid, 2014a, p. 15), and, similarly, the group has "something like an integrated shared perspective" that involves an awareness of "the difference between how 'we,' together, look at things, and the things as they are" (Schmid, 2014a, p. 17). (iii) In terms of commitment, Schmid argues that both singular and plural self-awareness commits one to "minimal consistency" (Schmid, 2014a, p. 16). In the plural case, this becomes a "constant normative pressure for coherence between the attitudes of interacting individuals" (Schmid, 2014a, p. 18). ${ }^{4}$

The promise of the plural self-awareness thesis is that it attempts to combine the awareness condition and the coalescence condition in a pre-reflective way. Plural self-awareness seems to be compatible with the idea that some shared actions are pre-reflective because plural self-awareness enables us to have shared attitudes without us being thematically aware of our co-agents and without requiring intellectually demanding forms of common knowledge. If, in pre-reflective action, I am aware of myself as being drawn to act by the situation, we might also occasionally be plurally self-aware that we are drawn to act by the situation. Further, Schmid suggests that plural self-awareness is irreducible to and perhaps even developmentally and explanatorily prior to singular self-awareness (Schmid, 2005, 2014a, p. 23). This relates to what I called the genetic problem, namely, how to account for the emergence of collective intentions out of presumably basic individual intentions without presupposing that the relevant individuals are already capable of seeing the world from a shared perspective. Schmid considers this approach to be wrong-headed and rejects the assumption that collective intentions are somehow built out of individual

\footnotetext{
4 To be sure, Schmid also admits that there are important differences between singular and plural selfawareness, e.g. "the singular 'sense of self' (...) establishes an authoritative point of view for which there is no equivalent in the plural case" (Schmid, 2014a, p. 23), but these are not pertinent for our discussion.
} 
intentions; instead, he claims that our capacity to see the world from a shared perspective is explanatorily basic.

Despite this promise, an ambiguity of Schmid's account throws doubt on the utility of the nation plural self-awareness for conceptualising shared action. More specifically, Schmid glosses over the fact that the phenomenological tradition offers not one but two accounts of pre-reflective self-awareness. Roughly, the first type is associated with what is sometimes called "transcendental phenomenology," while the second type is associated with what is sometimes called "existential phenomenology." As it turns out, it matters a great deal on which type of singular selfawareness we choose to construct plural self-awareness. ${ }^{6}$

Atomistic singular self-awareness is Husserlian in spirit. It names the formal unity of the mind afforded by a transcendental subject that unites distinct experiences in a single stream of consciousness. On this view, self-awareness is not something added to the experience but is, rather, an intrinsic feature of the experience itself; it is what makes an experience an experience for me. Zahavi calls it the minimal or experiential self by which he means to suggest that this type of self-awareness is formal insofar as it says nothing about the personal characteristics of an individual. This type of self-awareness is atomistic since it is not "constitutively dependent upon social interaction" (Zahavi, 2014, p. 95). Indeed, atomistic singular self-awareness is formal in the sense that it is entirely independent of whatever the subject directs itself towards; it is, rather, a permanent feature of the subject's experiential life.

Holistic singular self-awareness is the alternative type of self-awareness advocated by existential philosophers like Heidegger. For this reason, I will sometimes call it "the existential self." In contrast to the minimal self, the existential self targets the pre-reflective sense of self that is intrinsic to our practical engagement with the world and with other people. Like its atomistic counterpart, this self-awareness is given non-inferentially and non-observationally. Yet, holistic singular self-awareness is not formal. Rather, it is the sense of self that is intrinsically bound to how concrete situations appear to us in light of our everyday projects and engagement with other people. It is the pre-reflective self-awareness "reflected back to me" based on how the world solicits me to act. Formally put,

Holistic singular self-awareness is the sense of self inherent to how a social and physical environment solicits actions based on (a) the affordances inflected by the individual's abilities and dispositions and (b) the individual's self-referential commitment to a project that is furthered through these affordances.

In this definition, (a) designates that environments afford different things from different agents based on the agent's know how. Affordances are, hence, neither objective nor subjective but a correlation between the objective relations available in the environment and the abilities and dispositions of the agent. (b) refers to the

\footnotetext{
5 See Rousse (2018) for a comparison.

${ }^{6}$ It is somewhat curious that Schmid does not discuss these two types of self-awareness in any detail as his earlier work, in contrast to his more recent work, endorses the existential conception of self-awareness (Schmid, 2005, 2009).
} 
fact that not all affordances are salient. According to Heidegger, what accounts for this fact is how the agent's self-understanding ties in with his or her activities. For instance, teacher-affordances are salient to me if I am committed to the project of teaching. Heidegger calls this the "for-the-sake-of" thereby suggesting that in order for something to be significant or salient an agent must be doing it for the sake of some particular self-understanding (Heidegger, 1962, p. 114ff). For-the-sake-of relations tie agents to the affordances of their environment because the agent's practical self-awareness as this or that determines which set of in-order-to's, which practical possibilities, show up as salient rather than as mere affordances with no normative force. The agent must be self-referentially committed to some project for an environment to solicit actions.

This is not necessarily a deeply personal type of commitment. Sometimes the commitment underlies trivial cases like an agent being drawn to the chips in the buffet rather than the salad. Yet, this trivial solicitation can only get a grip on the agent if he or she is committed to some kind of project, say, the project of wanting to taste deliciously deep-fried food. In the words of Wrathall, "[w]hat makes me me and you you (...) is that each of us is, in virtue of our projects, a different way of 'polarizing' (...) those aspects of a situation that guide action." To be an agent is to be "a particular style of polarizing the affordances of a situation into particular solicitations to act" (Wrathall, 2017, p. 229). Although rather minimal, this kind of polarisation necessarily requires commitments because the agent cares about the activity in a way that can succeed or fail, e.g., if the chips turn out to be soggy and under seasoned. By themselves affordances are inert; they only become solicitations once someone cares about or commits to them. Borrowing a few terms from Steven Crowell, we might say that goals and affordances are "telic," while commitments are an "atelic" underpinning that render these goals and affordances worthwhile to someone (Crowell, 2013, p. 273).

Such polarising commitments are self-referential because they resist further explanation. I am drawn to the chips because I simply care about tasting them. "Selfreferential" does not mean, however, that the agent deliberately chooses his or her commitments. To the contrary, our commitments are part and parcel of the solicitations. Indeed, in most cases, we barely take notice of our commitment as we are too busy pursuing the teleological steps of our project (getting to the buffet, picking up a plate, and scoping over a handful of chips...). Nonetheless, it makes sense to say that we are non-thematically aware of our commitments since they are a constituent feature of the teleological steps that thematically occupy our attention and since they can be brought to the forefront of our attention if, for instance, our project fails.

This type of self-awareness is holistic because it names a non-thematic awareness of oneself as normatively engaged with an environment consisting of worldly objects and other people. A non-thematic sense of self, as committed to this or that project or self-understanding, is reflected back to us by the solicitations that draw us in.

The distinction between atomistic and holistic self-awareness reveals two problems for the attempt to use Schmid's account of plural self-awareness to grasp the nature of pre-reflective shared action. First, since atomistic self-awareness is a permanent feature of our experiential life, it cannot help us identify the self-awareness 
necessary to distinguish pre-reflective action from bodily happenings. We cannot experience the failure of atomistic self-awareness since atomistic self-awareness is a necessary condition for having an experience in the first place. Pre-reflective action implies an immanent measure of success, as I have argued, and since we cannot experience the success or failure of atomistic self-awareness, it cannot help us distinguish pre-reflective action from bodily happenings. If I see my arm soar into the air because it is triggered by the implanted microchip, this is still an experience for me. My atomistic self-awareness remains the same. From the perspective of holistic self-awareness, however, things look very different. On this account, I would not recognise the activity as mine if, for instance, I am unaware of any affordances in response to which it would make sense for me to raise my arm. Here, the activity would fail to satisfy one of the immanent measures of success characteristic of prereflective action, namely, condition (a) above. We can also imagine another case, akin to alien hand-syndrome, where my left hand, when triggered by the microchip, gets a 'mind of its own' in the sense that it responds purposefully to affordances in my immediate environment (such as unbuttoning my shirt), but in this case, my activity does not count as pre-reflective action because the activity does not satisfy the other immanent measure of success, namely, condition (b) according to which I must be self-referentially committed to a project that is furthered through the affordances to which my activity responds. In this example, I simply do not recognise the purposes and responses of the alien hand as part of one of my projects and, thus, I am not aware of myself as successfully performing the activity in question. ${ }^{7}$

Second, Schmid fails to recognise that only one form of pre-reflective self-awareness can be pluralised in shared action. As noted above, atomistic self-awareness is a permanent feature of the subject's experiential life; yet, in accounting for prereflective shared action, we need to show how an environment occasionally prompts $u s$ while it, in other circumstances, prompts me to act in a certain way. The selfawareness intrinsic to shared action cannot, in other words, be formal in the sense described above, but must rather be "reflected back to us" from a specific engagement with the world. Schmid does, at times, acknowledge that social relations and plural self-awareness are transitory (Schmid, 2014a, p. 22), yet he seems to consider plural self-awareness to be analogous to atomistic singular self-awareness when he claims that singular self-awareness "establishes something like the formal unity of mind" and "plays the role of Kant's 'transcendental apperception"” (Schmid, 2014a, p. 15). Like Zahavi's minimal self, Schmid's singular self-awareness is the unity of a stream of consciousness or the immanence of consciousness to itself. According to this analogy, Schmid's plural self-awareness "formally unifies our social mind" (Schmid, 2014a, p. 17), that is, independently of whatever is experienced. I contend,

\footnotetext{
7 As a third variation of this example, we can imagine that the person controlling my hand through the microchip knows me so well that they make my hand respond only to the environmental affordances that aligns with my self-referential commitments. This activity would be distinguishable from reflective action, since my hand would then move without me consciously representing the mental states that in normal deliberative circumstances make it do so, but indistinguishable from pre-reflective action. Yet, it seems to me that this is still very different from a mere bodily happening.
} 
on the other hand, that 'our social mind' must be unified by the solicitations that prompt us to respond.

In short, my suggestion is, first, that holistic self-awareness helps us explain the nature of pre-reflective action and, second, that a plural version of holistic selfawareness will help us explain the nature of pre-reflective shared action. Extrapolating from the previous definition, we get the following (preliminary) definition of this type of plural self-awareness:

Plural self-awareness is the sense of self inherent to how a social and physical environment solicits actions based on (a) the affordances inflected by a group's abilities and dispositions and (b) the group's self-referential commitment to a project that is furthered by these affordances.

The upshot of this redefinition is that it retains the main pro of Schmid's original proposal by not assuming shared action to involve the intellectually demanding representation of mental states and that it, in addition, allows us to account for the transience of plural self-awareness by way of our relations to other people and our environment while remaining true to the phenomenology of pre-reflective action.

\section{Joint goals and joint commitments}

I will now argue that the holistic model's way of tying together self-awareness and action provides a highly nuanced account of shared actions that effectively integrates both teleological and normative features of shared action. In the next section, I will spell this out in a taxonomy of individual and shared actions, but first we have to consider, in more detail, how the idea that the environment solicits actions from an agent can be translated from individual actions to shared actions.

I suggested that a solicitation requires two elements: (a) the affordances inflected by the agent's (or agents') suite of abilities and dispositions and (b) the agent's (or agents') self-referential commitment to a project that is furthered through these affordances. With Heidegger we can also call these elements for (a) in-order-to's and (b) for-the-sake-of's.

When it comes to (a) affordances, we should first note that, for human agents, environmental affordances are inherently connected to the various relations that connect us to other people. To take a Heideggerian example, the hammer affords hammering because the craftsman has been commissioned by someone to make the product. Here the environment affords something in light of a backgrounded understanding of the practical possibilities of someone else. Similarly, when two people are present in the same immediate environment, each agent pre-reflectively tracks and responds to the behaviour of the other. For instance, I pre-reflectively step aside in order for you to pass me in the narrow hallway. Our immediate understanding of our environment is thus already saturated by our non-thematic understanding of what others can and will do. This pre-reflective tracking and responsiveness will sometimes coalesce into joint affordances. In such cases, something appears as an affordance for us rather than just for me. This happens, for instance, when an environment affords something that I could not have done alone. Imagine, for instance, 
that you participate in the Black Lives Matter protest in The Centre in Bristol. A statue of the slave trader Edward Colston towers above this public space. You are enraged by this commemoration, and suddenly you see that someone has tied a rope around the statue. With a few of your fellow protesters, you start pulling the rope, ultimately toppling the statue. The environment solicits you to act together in light of the group's abilities and dispositions in a way that it simply would not do if you had walked past the statue on your own.

It is more controversial whether (b) the commitments or for-the-sake-of's can be put in the plural. How can a group self-referentially commit to some of these affordances? It is often assumed that for-the-sake-of's are individual, but I want to make the case that self-referential commitments can be joint in the sense that my selfreferential or atelic commitment to a project constitutively depends on your being similarly committed. ${ }^{8}$

To see this, let's take an example from Heidegger that explicitly describes joint goals but which, with a bit of modification, can also shed light on joint commitments. Heidegger describes two campers, where one chops wood while the other peels potatoes:

They are with each other-and not just because they are in the vicinity of each other. They are with one another, although they are occupied with different things, yet for the same purpose, namely, with the preparation of the meal and, further, with taking care of their stay in the cabin. (Heidegger, 1996, p. 91)

At the face of it, this looks like Bratman's teleological account. The two campers engage in shared action because they intend the same goal, namely, the preparation of the meal and the stay at the cabin, and they have meshing subplans. For Heidegger, however, the two campers are oriented towards their joint goal pre-reflectively, whereas Bratman construes this is a deliberative process. Peeling potatoes is significant in order to make the meal, which is significant in order to stay at the cabin, but the campers do not actually think about their joint goal. It is simply part of the intentional background that guides their actions. If we imagine that one camper had a cold and cancelled, but the other camper went on the trip anyway, he could still unreflectively engage in chopping wood and thus his state of mind, understood internalistically, would remain the same. Yet, Heidegger would insist that without the tacit reference to his friend, the activity would no longer make sense in the same way since the non-thematic goal would no longer be a joint goal but now only an individual goal.

\footnotetext{
${ }^{8}$ Haugeland claims that existential commitments are "crucially not social" (Haugeland, 1998, p. 5), and Crowell maintains that only the "I-myself"-the first-person singular-can be authentically committed to the norms that governs its behaviour (e.g. Crowell, 2013, p. 298). Sánchez Guerrero's (2016) Heideggerian approach to collective emotions (what he calls "affective intentional community") is a notable exception. He agrees that Heidegger's for-the-sake-of should be understood as a tacit self-reference intrinsic to an individual's intentional acts, but that it is also possible that "others are referentially included in the intentional structure of the emotions at issue by way of a tacit self-reference, and not by way of a second- or third-personal indication" (Sánchez Guerrero, 2016, p. 176).
} 
However, we must also account for the for-the-sake-of that, ex hypothesi, affects how the environment of wood and potatoes solicits actions from the campers. Suppose that the campers are a father and his teenage son. Father and son have planned their camping trip a few weeks in advance but in the days before their departure, the teenage son becomes inexplicably moody. The son is conscientious and does not try to bail on the camping trip, although he complains a lot. During the trip, he constantly listens to angry music with his headphones, and he keeps a gloomy look on his face while peeling the potatoes. Do father and son correctly coalesce in shared action? They did, of course, coordinate their actions in pursuit of the joint goal of camping. However, another sense of the we seems missing. Despite their coordination and their joint goal, father and son are to some extent performing their tasks next to rather than with each other.

Neither Bratman nor Gilbert sees any substantial difference between these two examples. Bratman would say that each intends that they go camping, that they have correctly meshing subplans, and that they operate under conditions of common knowledge. For Gilbert, the decisive part is that father and son constituted a plural subject when they expressed their initial readiness to go on the camping trip and that they emulated a single body in doing so. On this account, the attitude of the sulky teenager is beyond rebuke, and, tellingly, Gilbert maintains that joint commitments hold even under coercive circumstances (Gilbert, 1993). In contrast, I believe that there is a significant difference between the two cases and that the latter case misses a crucial feature of genuine joint action even though a joint goal is intended and achieved.

In brief, the difference consists in how the father and son relate to their joint goal. What is similar between the two cases is the set of in-order-to's and what differs are the for-the-sake-of's. The happy campers have a joint goal and a joint commitment. Father and son go camping as an end-in-itself, as we might say with reference to Kant (cf. Heidegger, 1982, p. 170). They go camping for the sake of doing something together, and the affordances of the situation prompt them to act in a specific way only in light of this joint commitment.

The father to the sulky teenager also intends to go camping for the sake of doing something with his son. Yet, the teenager does not share this commitment. He is motivated by a different for-the-sake-of than his father. Perhaps the son simply goes camping because he does not want to get blamed for cancelling the trip. In any case, the son pursues the joint goal in light of an individual rather than joint commitment. For the father, this means that his for-the-sake-of breaks down as it constitutively depends on being shared by the son, and this alters what the environment solicits from him. The possibility of lighting a fire is now less salient than, say, the possibility of going to bed early. The trip is a failure for the father, not because father and son did not carry out the joint goal that they had agreed upon, but because he tried to do something for the sake of doing something together with his son and, alas, his son did not share this commitment. ${ }^{9}$

\footnotetext{
9 Sánchez Guerrero makes a comparable point when he argues that it is possible for a number of individuals to pursue not only the actualization of a certain possibility but also to do so as a group, i.e., by understanding themselves as group-members who act for the sake of the 'wellbeing' or 'flourishing' of the group that they constitute (e.g. Sánchez Guerrero, 2016, p. 257). I agree with Sánchez Guerrero that
} 
This shows that the existential joint commitment is not tantamount to a reflective endorsement; it is pre-reflective in the sense that it is an integral feature of how a shared environment solicits people to response. It is the condition in light of which environmental affordances prompts us to act. As a commitment, it retains a normative element, however, since our project can succeed or fail in a way that is independent of the mere teleology of the action. The sulky teenager shows that the success or failure of shared action is not only measured by whether we achieve the goals that we aim for but also by whether others on which our commitment depends turn out to be similarly committed. In contrast to Schmid, who understands joint commitment as the "constant normative pressure for coherence between the attitudes of interacting individuals" (Schmid, 2014a, p. 18), the existential account of joint commitments does not concern coherence between attitudes as such but the fact that we sometimes care about things because we simply assume this care to be shared by others. ${ }^{10}$ As the disappointed father might complain: "I just wanted us to do something together for once!".

It is central to Gilbert's reflective concept of joint commitments that they provide us with obligations and entitlements. For her, joint commitments are the battle ground on which we coerce others to do their parts by invoking the rights and duties that we conferred upon each other when we expressed our readiness to undertake a joint commitment. Gilbertian joint commitments are thus in no way opposed to reflection. In fact, they come must fully into view when we explicitly remind each other and ourselves that we are jointly committed to do something as a single body. Existential joint commitments are very different for the father only feels the need to explicitly remind the son of their agreement to go camping because their existential joint commitment has already gone awry. When pre-reflective shared action succeeds, things go smoothly and we don't feel the need for overt normative exchanges. This need only arises because the campsite no longer solicits father and son to spend quality time with each other. Thus, when the father explicitly reminds his son-and perhaps himself - that they agreed to go camping and have a good time, their pre-reflective action has already been replaced by a reflective substitute in which we recall and represent our intentions, beliefs, common knowledge, obligations, and so on.

\footnotetext{
Footnote 9 (continued)

it is important to distinguish between the joint possibility or goal that the individuals try to actualise, on the one hand, and whether they do so as a group or as individuals, on the other hand. I think, however, that it is misleading to say that the individuals must act for the sake of the group's wellbeing or flourishing since this seems to require a prolonged concern for the group and that we entertain certain beliefs about the desires and goals of the group that lie beyond the concrete goal currently being pursued. Instead, I propose that the joint for-the-sake-of requires that the individuals are committed to the project only if the others are similarly committed.

10 To put the point differently, existential joint commitments do not concern the coherence or consistency of our attitudes due to the fact that when we act pre-reflectively, we do not question whether or not the attitudes of our co-agents cohere with our own. We simply act on the tacit assumption that they do. The question whether our attitudes do in fact cohere only arises, when pre-reflective shared action breaks down and we enter a reflective mode. This means that each of us might experience something as a shared action to which we are jointly committed even if it later turns out that we were wrong to tacitly assume others to be thus committed. Joint commitments are intrinsic to the first-person perspective but fallible. As Heidegger once noted, in a passage where he uses 'decision' [Entscheidung] to refer to the for-the-sake-of: "no individual among you can in any manner ascertain about how any other individual has decided" (Heidegger, 2009, 51).
} 
At this point of the camping trip, I imagine that things can go one of two ways. Either the reproach is successful and the son tells what has been bothering him after which father and son can finally enjoy their trip. In this case, the shared action becomes, once again, pre-reflective. Or father and son sit in awkward silence for the rest of the night deliberately forcing themselves to remain seated although the fire no longer solicits them to sit there, although the fire has lost its magic. In this case, the shared action remains reflective.

\section{A taxonomy of individual and shared actions}

I suggested earlier that something counts as shared action when an environment solicits behaviour based on (a) the affordances inflected by a group's abilities and dispositions and (b) the group's self-referential commitment to a project that is furthered by these affordances. We now see that the logical operator should not be a conjunction but an inclusive disjunction since (a) affordances and (b) self-referential commitments can be singular or plural independently of each other. We thus end up with a fourfold taxonomy of how an environment solicits actions that combines the goal orientation of Bratman's account and the normative dimension of Gilbert's in a single phenomenological framework.

In the simplest case, both goal and commitment are singular:

An environment solicits action based on (a) the affordances inflected by an individual's abilities and dispositions and (b) the individual's self-referential commitment to a project that is furthered by these affordances.

The environment affords certain possibilities because of what the individual is able and disposed to do. These affordances are made into solicitations by the agent's commitment to actualise one rather than another possibility. For example, my laptop affords me to work since I know the password, and since I know how to open up the manuscript file, and so on. This affordance is a solicitation because I try to be an academic. Of course, the solicitation depends on anonymous social institutions but does not refer directly to other people and is hence an individual action, or, more precisely, an individually coordinated individually committed action.

Another possibility is the following:

An environment solicits action based on (a) the affordances inflected by a group's abilities and dispositions and (b) an individual's self-referential commitment to a project that is furthered by these affordances.

If we pluralise (a) the affordances but not (b) the commitment, we have what I'll call coordinated action or, technically, jointly coordinated individually committed action. My example with the sulky teenager falls in this category because the teenager acts in pursuit of a joint goal although he is committed to this goal as an individual. The teenager pursues a joint goal for his own sake. 
The third type of action pluralises (b) the commitment but maintains that (a) the affordances are given to an individual:

An environment solicits action based on (a) the affordances inflected by an individual's abilities and dispositions and (b) a group's self-referential commitment to a project that is furthered by these affordances.

In individually coordinated jointly committed action, I do something for the sake of us. In this case, a number of individuals could, for instance, collectively agree to emulate not, as Gilbert would have it, a collective body but rather collectively agree to emulate individual bodies. This might be of little real-world significance but the combination does explain a few counterexamples that trouble other accounts of collective intentionality. Searle, for instance, discusses a case where a group of business school graduates, who were taught Adam Smith's theory of the invisible hand, get together on graduation day and swear to each other that they will help humanity by getting as rich as they can by acting as selfishly as they can (Searle, 2010, p. 48). Qua their promise to each other, the individuals may act selfishly for the sake of doing something together, even though they only rely on their own individual abilities and dispositions in doing so.

Joint action, in contrast, requires the highest degree of social cooperation since it pluralises both (a) affordances and (b) commitments:

An environment solicits action based on (a) the affordances inflected by a group's abilities and dispositions and (b) a group's self-referential commitment to a project that is furthered by these affordances.

In jointly coordinated jointly committed action, multiple agents are jointly solicited to act on affordances inflected by their joint abilities and dispositions. Sometimes this requires close cooperation, e.g., when a group of protesters topple a statue. At other times this involves cooperation between multiple activities that could in principle be carried out by individuals separately, e.g., chopping wood and peeling potatoes. Either way, joint action also requires that the agents self-referentially commit to these affordances as a group. They commit self-referentially as a group when the commitment of each individual constitutively depends on the others being similarly committed. They thereby realise a joint goal for the sake of doing something together.

Of course, one might object that real actions are much messier than this taxonomy suggests. It might be unclear to me whether I dance for the sake of us or whether I dance for my own sake. Although difficult to discern at times, the commitment is still operative in the solicitation. This is clear from the fact that shared action can fail in terms of not only joint goals but also joint commitments. Sometimes I simply get the feeling that other people are not committed to what "we" do, that they only do it for themselves. If this lessens or otherwise changes the salience of the situation, my commitment was indeed joint. 


\section{Conclusion}

I have argued that we should conceptualise action on the basis of how an environment solicits someone to behave based on (a) the affordances or goals inflected by their abilities and dispositions and (b) their self-referential commitment to a project that is furthered by these affordances. This definition of action is sufficiently flexible to account for not only individual action (in which both (a) and (b) refer only to an individual) but also several distinct subtypes of shared action. Thus, behaviour counts as shared action if and only if it is prompted by a solicitation in which either (a) the goals, or (b) the commitments, or both (a) the goals and (b) the commitments are joint. We thereby get three distinct subtypes of shared actions: (i) jointly coordinated individually committed action, (ii) individually coordinated jointly committed action, and (iii) jointly coordinated jointly committed action.

My account improves on existing accounts of shared action in several ways. First, in terms of the intellectualist problem, I have argued that we do not necessarily have to consciously represent the mental states of ourselves and others in order to act together. Instead, I have argued that some forms of shared action are pre-reflective in the sense that we are prompted to act by our immediate environment on the tacit assumption that others will also do so. This form of shared action does not require that we reflect upon (not even that we are capable of reflecting upon) the mental states of others but only that we pre-reflectively track and respond to their behaviour. Second, in terms of the taxonomy problem, my account covers both the teleology and the normativity of shared actions showing how they interrelate and how they differ from each other. More specifically, I have argued that in solicitations there are both a teleological and a normative element and that each of these can refer either to the agent as an individual or to a group of which the agent is a part. Third, I have avoided the genetic problem by refusing to explain shared actions and intentions as a phenomenon that emerges out of individual actions and intentions. Rather, I have described individual action and (the three types of) shared action as different varieties of the same basic mechanism, namely, our pre-reflective responsiveness to our shared environment. ${ }^{11}$

Acknowledgements This work has been generously supported by the Carlsberg Foundation and a Junior Research Fellowship at Linacre College, Oxford. I am grateful to Mark Wrathall, Dan Zahavi and the anonymous reviewers for helpful comments on earlier versions of the manuscript.

Open Access This article is licensed under a Creative Commons Attribution 4.0 International License, which permits use, sharing, adaptation, distribution and reproduction in any medium or format, as long as you give appropriate credit to the original author(s) and the source, provide a link to the Creative Commons licence, and indicate if changes were made. The images or other third party material in this article are included in the article's Creative Commons licence, unless indicated otherwise in a credit line to the material. If material is not included in the article's Creative Commons licence and your intended use is not permitted by statutory regulation or exceeds the permitted use, you will need to obtain permission directly from the copyright holder. To view a copy of this licence, visit http://creativecommons.org/licen ses/by/4.0/.

\footnotetext{
11 A longer and slightly reworked version of this article will appear as chapter 5 of my book Heidegger's Social Ontology: The Phenomenology of Self, Worldand Others (Cambridge University Press, 2022).
} 


\section{References}

Bratman, M. (1999). Faces of intention: Selected essays on intention and agency. Cambridge University Pres.

Bratman, M. (2013). Shared agency: A planning theory of acting together. Oxford University Press.

Crowell, S. G. (2013). Normativity and phenomenology in husserl and heidegger. Cambridge University Press.

Dreyfus, H. (1991). Being-in-the-world: A commentary on Heidegger's being and time. MIT Press.

Dreyfus, H. (2014). Skillful coping: Essays on the phenomenology of everyday perception and action. Oxford University Press.

Dreyfus, H., \& Dreyfus, S. (1988). Mind over machine: The power of human intuition and expertise in the era of the computer. Free Press.

Gilbert, M. (1990). Walking together: A paradigmatic social phenomenon. Midwest Studies in Philosophy, 15(1), 1-14.

Gilbert, M. (1992). On social facts. Princeton University Press.

Gilbert, M. (1993). Agreements, coercion, and obligation. Ethics, 103(4), 679-706.

Gilbert, M. (2013). Joint commitment: How we make the social world. Oxford University Press.

Haugeland, J. (1998). Having thought: Essays in the metaphysics of mind. Harvard University Press.

Heidegger, M. (1962). Being and time (J. Macquarrie \& E. S. Robinson, Trans.). Blackwell.

Heidegger, M. (1982). The basic problems of phenomenology (A. Hofstadter, Trans.). Indiana University Press.

Heidegger, M. (1996). Einleitung in die Philosophie. Vittorio Klostermann.

Heidegger, M., (2009). Logic as the question concerning the essence of language (W. T. Gregory and Y. Unna, Trans.). State University of New York Press

Høffding, S. (2019). A phenomenology of musical absorption. Palgrave Macmillan.

Ludwig, K. (2016). From individual to plural agency: Collective action (Vol. 1). Oxford University Press.

Mathieson, K. (2005). Collective consciousness. In D. W. Smith \& A. L. Thomasson (Eds.), Phenomenology and philosophy of mind (pp. 235-252). Clarendon Press.

Merleau-Ponty, M. (2012). Phenomenology of perception (D. Landes, Trans.). Routledge.

Petersson, B. (2007). Collectivity And circularity. The Journal of Philosophy, 104(3), 138-156. https://doi. org/10.5840/jphil2007104329

Rousse, B. S. (2018). Self-awareness and self-understanding. European Journal of Philosophy, 27(1), $162-186$.

Sánchez Guerrero, H. A. (2016). Feeling together and caring with one another: A contribution to the debate on collective affective intentionality. Springer International Publishing.

Schmid, H. B. (2005). Wir-Intentionalitat. Kritik des ontologischen Individualismus und Rekonstruktion der Gemeinschaft. Verlag Karl Alber.

Schmid, H. B. (2009). Plural action: Essays in philosophy and social science. Springer Science \& Business Media.

Schmid, H. B. (2014a). Plural self-awareness. Phenomenology and the Cognitive Sciences, 13(1), 7-24.

Schmid, H. B. (2014b). The feeling of being a group: Corporate emotions and collective consciousness. In C. von Scheve \& M. Salmela (Eds.), Collective emotions: Perspectives from psychology, philosophy, and sociology (pp. 3-16). Oxford University Press.

Schmid, H. B. (2018). The subject of "We intend." Phenomenology and the Cognitive Sciences, 17(2), 231-243.

Schweikard, D. P., \& Schmid, H. B. (2013). collective intentionality. The Stanford Encyclopedia of Philosophy.

Searle, J. (1990). Collective intentions and actions. In P. R. C. Jerry Morgan \& M. Pollack (Eds.), Intentions in communication (pp. 401-415). MIT Press.

Searle, J. (1995). The construction of social reality. The Free Press.

Searle, J. (2001). Neither phenomenological description nor rational reconstruction. Revue Internationale De Philosophie, 55(216), 277-284.

Searle, J. (2010). Making the social world: The structure of human civilization. Oxford University Press.

Tomasello, M. (2014). A natural history of human thinking. Harvard University Press.

Tomasello, M., \& Carpenter, M. (2007). Shared intentionality. Developmental Science, 10(1), 121-125. https://doi.org/10.1111/j.1467-7687.2007.00573.x

Walsh, P. (2019). Intercorporeity and the first-person plural in merleau-ponty. Continental Philosophy Review, 53, 21-47. https://doi.org/10.1007/s11007-019-09480-x 
Wrathall, M. (2014). Autonomy, authenticity, and the self. In D. McManus (Ed.), Heidegger, authenticity and the self: Themes from division two of being and time (pp. 193-214). Routledge. https://doi.org/10.4324/ 9781315771861-13

Wrathall, M. (2017). I" "here" and "you" "there. Yearbook for Eastern and Western Philosophy, 2017(2), 223-234.

Zahavi, D. (2014). Self and other: Exploring subjectivity, empathy, and shame. Oxford University Press.

Zahavi, D. (2015a). Self and other: From pure ego to co-constituted we. Continental Philosophy Review, 48(2), 143-160.

Zahavi, D. (2015b). You, me, and we: The sharing of emotional experiences. Journal of Consciousness Studies, 22(1-2), 84-101.

Zahavi, D. (2018). Collective intentionality and plural pre-reflective self-awareness. Journal of Social Philosophy, 49(1), 61-75.

Zahavi, D. (2019). Second-person engagement, self-alienation, and group-identification. Topoi, 38(1), 251-260. https://doi.org/10.1007/s11245-016-9444-6

Publisher's note Springer Nature remains neutral with regard to jurisdictional claims in published maps and institutional affiliations. 